\title{
Developing a model of carbon sources and sinks for Indigenous communities in Australia
}

\author{
J. Stewart, R.J. Harper and M. Anda \\ School of Environmental Science, Murdoch University, Western Australia \\ Email: joanne.stewart@murdoch.edu.au
}

\begin{abstract}
The transition to a low carbon economy provides potential opportunities for Indigenous communities living in remote areas of Australia. Recent studies and trial projects indicate a range of potential benefits from carbon management programs such as early season fire management, bio-sequestration, bioenergy production, and energy monitoring services. Remote Indigenous communities in Australia typically have few employment opportunities, and the health and socio-economic statistics of residents indicate several disadvantages compared to the average non-Indigenous Australian. Despite this many communities maintain a strong culture and a wealth of traditional knowledge, particularly in relation to natural resource management. These carbon management programs offer potential employment and business development prospects that utilise Indigenous knowledge and are in keeping with their caring for country preferences.
\end{abstract}

There is little published information on the carbon profiles of these communities but they are expected to be highly carbon intensive due to their frequent reliance on diesel-powered electricity generators, fossil-fuelled vehicles that need to travel vast distances and housing that often requires energy-intensive thermal conditioning. Hence, efforts are also required to help reduce carbon emissions and associated costs, particularly rising electricity and fuel prices from direct use or those embedded in goods and services.

To ascertain whether implementation of proposed carbon management programs can be combined to mitigate carbon emissions a method for estimating and comparing emission abatement across a range of scenarios is required. A carbon accounting model that quantifies the estimated carbon that can be mitigated from sources and sequestered in sinks for a given community has been developed. The model combines two methods of measurement: life cycle analysis and land use modelling techniques.

LCA is an assessment of impacts throughout a product's life, or "cradle to grave", including raw material acquisition, through production, use and disposal. The AS/NZS ISO standard 14040:1998 Environmental Management- Life cycle assessment - principles and framework outlines the requirements and process for undertaking a life cycle impact assessment. The life cycle analysis is applied in the model to estimate key emission sources for greenhouse gases broadly categorised as follows: materials used for construction and maintenance, construction processes including transport, operating energy supply and demand, transport during the occupancy phase, water systems, and solid waste. Because a full life cycle analysis can be a time and data intensive undertaking only significant items in the community are included and some emissions related to transport and waste are based on annual inventory methods only.

Embedded within the life cycle analysis is the model to estimate carbon sinks. The carbon sinks are modelled using a method in accordance with IPCC guidelines for land use, land use change and forestry (LULUCF). This takes into account conversions for a variety of land use categories and, where significant, sub-categories of biomass, dead organic matter and soil. This allows sinks to be estimated within defined limits of uncertainty and a total sequestration quantity to be approximated.

The combination of the two measurement methods provides an overall carbon cycle for a community and an estimate of the potential to provide climate change mitigation capacity including a quantitative basis for further economic analysis.

Keywords: Life Cycle Analysis (LCA), Carbon Inventory, Indigenous Communities 


\section{INTRODUCTION}

The transition to a low carbon economy provides potential opportunities for Indigenous communities in remote areas of Australia. Recent studies and trial projects indicate a range of potential benefits from carbon management programs such as early season fire management, bio-sequestration, bio-energy production, and energy monitoring services. In addition, there has been widespread degradation of land as a result of grazing in arid, inland Australia. In Western Australia, for example, Noble et al. (1996) summarised several rangeland condition surveys in Western Australia, with 50 to $94 \%$ of the land considered to be in a "deteriorating" or "degraded" condition. Carbon mitigation through activities such as destocking or reforestation may provide a means of rehabilitating these lands (Harper et al., 2007). The rehabilitation of rangelands could provide potential mitigation of carbon emissions of $100 \mathrm{Mt}$ per annum, and changes in savanna burning $13 \mathrm{Mt}$ per annum (Eady et al., 2009).

There are many remote communities that are distributed across the rangelands of Australia, and are therefore well located to provide mitigation services in these areas. Currently, remote Indigenous communities in Australia typically have few employment opportunities, and the health and socio-economic statistics of residents indicate several disadvantages compared to the average non-Indigenous Australian (SCRGSP, 2009). Despite this many communities maintain a strong culture and a wealth of traditional knowledge, particularly in relation to natural resource management. Carbon management programs offer potential employment and business development prospects that utilise Indigenous knowledge and are in keeping with their "caring for country" traditions and preferences (Griffiths and Kinnane, 2011).

Research has also shown that small remote outstations that lead traditional active life styles and have access to health services have better health outcomes than centralised communities (McDermott et al., 1998). Therefore if carbon management programs can be designed to accommodate communities' cultural needs and goals there is potential for a suite of benefits to be delivered to the residents. While the overall model would need to also estimate these other benefits it is only the carbon calculation methodology that is considered in this paper.

A carbon accounting model that quantifies the estimated carbon that can be mitigated from sources and sequestered in sinks for a given community has been developed. The model combines two methods of measurement: life cycle analysis and land use modelling techniques.

\section{MODEL DESIGN}

As remote communities often have a settlement area and control of land via Native Title or pastoral lease, the model design accommodates carbon emissions related to settlement dynamics and land use. As the purpose of the model is to assess the abatement potential of changes to settlement inputs, dynamics and land use it needs to evaluate the energy and carbon emission investment value of a given program or technology over its useful life. Only significant greenhouse gas flows are included to ensure the method is cost efficient and can be conducted in a timely manner.

\subsection{Australia's emissions}

Australia produced net greenhouse gas emissions of approximately $600 \mathrm{Mt}$ of $\mathrm{CO}_{2}$-e during 2009 under the UNFCCC reporting framework, which quantifies an annual inventory of emissions in the year of occurrence (DCCEE, 2011b).

These emissions by sector are provided in Table 1 and it should be noted that LULUCF could provide a net source or sink depending on its management. However, the impact of individual settlement design on carbon emissions and the potential to mitigate are not well understood. To understand a settlement's impact the sources and sinks of key elements in its design and activities Table 1. Australia's net GHG emissions by sector under the UNFCCC, 2009 (DCCEE 2011b)

\begin{tabular}{|l|c|}
\hline Sector & $\begin{array}{c}\text { Emissions } \\
\left(\mathrm{Mt} \mathrm{CO}_{2}-\mathrm{e}\right)\end{array}$ \\
\hline Stationary energy & 294 \\
\hline Transport & 84 \\
\hline Fugitive emissions from fuel & 40 \\
\hline Industrial processes & 30 \\
\hline Agriculture & 85 \\
\hline Land use, land use change and forestry & 54 \\
\hline Waste & 14 \\
\hline Total & 600 \\
\hline
\end{tabular}
need to be mapped and measured. 


\subsection{Extended Metabolism Model}

The "extended metabolism model (EMM)" for human settlements (Newman, 1999) is based on the biological systems method of identifying resource inputs and outputs and augmented by acknowledging that settlements are dynamic systems with a range of active processes and liveability agenda. Therefore, in order to reduce waste outputs, including excess carbon emissions, consideration should be given to reducing resource inputs while maintaining required levels of settlement activity to meet desired liveability outcomes. Based on this, EMM emission sources identified for measurement include inputs of materials, water, and energy, processes of construction, energy demand and transportation, and outputs of solid and liquid waste. It should be noted that in natural ecosystems there is no "waste" and all elements are recycled for re-use in some way (Wright, 2005). Therefore, consideration should be given to continuous closed-loop cycling of elements in all settlement designs.

\subsection{Land Use Dynamics}

The 2006 IPCC Guidelines for National GHG Inventories (IPCC, 2006) provides generic methods to be applied for changes in land use across all six land categories: forest, croplands, grasslands, wetlands, settlements and other land uses. Annual changes in carbon stocks in these land categories will be the sum of changes in six identified pools: above-ground biomass (AB), below-ground biomass (BB), deadwood (DW), litter (LI), soils (SO) and harvested wood products (HWP). The changes to be estimated in these pools include:

- Increase of carbon stocks due to growth;

- Transfer of carbon between pools such as AB to DW, LI or HWP;

- Carbon fluxes due to discrete events such as disturbances like fire; and

- Carbon fluxes due to continuous processes such as decomposition.

\subsection{Model Sources and Sinks}

The model comprises a combination of identified emission sources, based on settlement metabolism and identified pools as follows:

- Sources: materials, construction processes, operating energy (supply and demand), transport, water systems and waste

- Sinks: above-ground biomass (AB), below-ground biomass (BB), deadwood (DW), litter (LI), soils (SO) and harvested wood products (HWP)

There will be key links between the carbon sources and sinks, such as harvested wood products becoming materials or fuel for the settlement system or water used to promote growth of above and below-ground biomass. It should be noted that some communities may have agricultural practices on their lands such as cattle management and bio-fuel production. The methods for modelling these are not discussed here but would be added to the model where quantities are significant.

\section{CARBON ACCOUNTING METHODS}

Currently there are two key accounting methods used for carbon accounting: the carbon inventory method and life cycle analysis (LCA). The inventory method measures annual carbon emissions and removals and is used to calculate Australia's National Greenhouse Gas Inventory each year, which is submitted to the UNFCCC and for KP reporting purposes. This method is useful for identifying and monitoring emission and removal sources and level changes from year to year. However, to assess and compare the energy investment of programs and technologies and the resources needed to operationalise them, another method is required.

\subsection{Life Cycle Analysis of Settlements}

LCA is an assessment of impacts throughout a product's life, or "cradle to grave", including raw material acquisition, through production, use and disposal (Standards Australia, 1998). The AS/NZS ISO standard 14040:1998 Environmental Management- Life cycle assessment - principles and framework outlines the requirements and process for undertaking a life cycle impact assessment. The International Energy Agency also recognises LCA as a valuable methodology for examining the energy and carbon of buildings (International Energy Agency Annex 31 Project, 2004) but also notes its challenges including: 
- large quantities of data are needed to quantify all inputs and processes;

- life expectancy of products need to be known or reliably estimated;

- the use and disposal of products may vary considerably between consumers; and

- shared processes and recycled products can be difficult to allocate.

A community is generally expected to have an infinite life with a range of energy transactions occurring during its lifespan. Therefore it is difficult to apply a complete life cycle analysis to an entire community. For the purpose of assessing a dynamic community system the model is limited to the following:

- Only significant embodied energy and emission source data are included, which are expected to be limited to buildings, and major plant and equipment items;

- Life expectancy of large individual components, such as buildings, will be included where they can be reasonably estimated. Total emissions can then be annualised over the expected life to approximate an average annual emission rate associated with the building.

- Energy use data will be modelled on actual use or estimated use based on available data;

- End-of-life aspects, such as demolition or recycling of buildings and infrastructure will not be included in the calculations as they are too uncertain. Only before-use and use phases will be included; and

- The system boundary will contain the geographical area of the community including land which it manages, plus direct transportation of goods and services.

Emissions from solid waste will only be included where significant and any major infrastructure needed to process the waste will be included with other material items.

\subsection{Land Use Inventories}

Under the 2006 IPCC guidelines for National Greenhouse Gas Inventories two different approaches to estimating carbon stocks are valid:

1. The process-based approach, which estimates the net balance of additions to and removals from carbon stocks; and

2. The stock-based approach, which estimates the difference in carbon stocks at two points in time.

The process method is more suitable for predictive modelling approaches and can use research-derived coefficients, which should allow for inter-annual variability. Both methods are approved for inventory measurement provided they can simulate effects of actual disturbances, varying trends and can be verified by actual measurement data.

The CENTURY model, developed by the Colorado State University and available on line (Colorado State University, undated), simulates plant-soil nutrient cycling, including carbon, over four land types: grasslands, agricultural systems, forests and savannas. Disturbance events such as fire, grazing, harvest and cultivation can be accounted for within the model. The system has been used to model changes in bio-sequestration under a range of scenarios on three pastoral leases in the WA rangelands (Alchin et al., 2010). For the purpose of the high level modelling required for the emission cycles in land use it can also be applied in the model outlined in this paper.

\subsection{Model Summary}

To account for carbon emission sources it is proposed that a mix of both life cycle analysis and carbon inventories on an annual basis be used as provided in Table 2.

Table 2. Community emission sources, methods and scopes

\begin{tabular}{|l|l|l|}
\hline Source & Method & Scope \\
\hline $\begin{array}{l}\text { Buildings and major infrastructure for } \\
\text { water, waste and energy supply }\end{array}$ & $\begin{array}{l}\text { Annualised } \\
\text { LCA }\end{array}$ & Materials, construction process, maintenance, operating energy \\
\hline Transport & Inventory & Fuel used by residents and for direct delivery of goods and services \\
\hline Waste & Inventory & Direct emissions from waste \\
\hline Land use & Inventory & $\mathrm{AB}, \mathrm{BB}, \mathrm{DW}, \mathrm{LI}, \mathrm{SO}$ and HWP \\
\hline
\end{tabular}




\section{CARBON PROFILE OF COMMUNITIES}

There is little published information on the carbon profiles of remote communities but they are expected to be highly carbon intensive due to their reliance on diesel-powered electricity generators, fossil-fuelled vehicles that need to travel vast distances and housing that often provides little thermal protection from the harsh climate. Hence, efforts are also required to help reduce their carbon emissions and associated costs, particularly rising electricity and fuel prices from direct use and those embedded in goods and services.

A study conducted in 2005 estimated a mid range of household energy use from a sample of 63 Northern Territory remote Indigenous community houses (Beale, 2006). The result for a 3-bedroom house with five occupants was energy use of $75 \mathrm{MJ}$ per day, including $15 \mathrm{MJ}$ for water supply plus $36 \mathrm{MJ}$ per day for solar hot water heating. As many remote communities are still using diesel generated electricity supply (Australian Bureau of Statistics, 2007), and assuming a primary energy to electricity ratio of 3:1, the above household would generate approximately $15.6 \mathrm{~kg} \mathrm{CO}_{2}$-e/day or approximately $5.7 \mathrm{t} \mathrm{CO}_{2}$-e/year.

\section{HYPOTHETICAL COMMUNITY EXAMPLE}

As data needs to be collected for the remaining elements of the model a hypothetical example is used to populate the model. Assumed attributes for a small community include: six three-bedroom brick veneer houses with solar hot water systems, a one-room school, a store, a diesel generator, a water bore and a landfill waste system. The residents use 40 litres of diesel for transport per week and deliveries use half of that quantity. Assuming a 35-year design life of the buildings, the total average carbon emissions would be 104.6 $\mathrm{t} \mathrm{CO}_{2}$-e/year as calculated in Table 3. Materials, construction process and recurring maintenance have been calculated using eTool (Haynes and Bruce, 2011) which is LCA software for buildings available online. If this community had 30 residents the carbon intensity would be approximately $3.5 \mathrm{t} \mathrm{CO}_{2}$-e per resident per year.

To calculate land use emissions and removals it is assumed the community has a 100 hectare site that is partially degraded due to grazing and is implementing management practices to allow some regeneration. Using results from the CENTURY model for a similar application in the rangelands (Alchin et al., 2010) removals could average between 0.4 and $2.0 \mathrm{t} \mathrm{CO}_{2}$-e/ha/year, depending on the management practice applied. Using the lower rate total removals would be approximately $41.0 \mathrm{t} \mathrm{CO}_{2}$-e/year.

Table 3. Greenhouse gas emissions calculations for a hypothetical community

\begin{tabular}{|l|c|c|c|}
\hline Item & Method & $\begin{array}{c}\mathrm{CO}_{2} \text {-e (t/year) } \\
\text { Proportion of total } \\
\text { emissions (\%) }\end{array}$ & 10.0 \\
\hline Materials (buildings and infrastructure) & Annualised LCA & 1.3 & 10 \\
\hline Construction process (including transport) & Annualised LCA & 3.3 & 3 \\
\hline Recurring materials, assembly and transport & Annualised LCA & 29.8 & 28 \\
\hline Operational energy & Annualised LCA & 33.5 & 7 \\
\hline Water systems & Annualised LCA & 16.7 \\
\hline Transport - residents & Inventory & 2.4 & 32 \\
\hline Transport - non residents & Inventory & 104.6 \\
\hline Waste emissions & Inventory & $(40.9)$ \\
\hline Total excluding LULUCF & & 63.6 \\
\hline LULUCF & & 16 \\
\hline Total including LULUCF & & 2 \\
\hline
\end{tabular}

The results indicate the significant emission categories in this community are transport needs of residents (32\%), operational energy (28\%), and transport of goods and services $(16 \%)$. This information highlights the areas residents may want to address and potential carbon market opportunities. It should be noted that there are a number of assumptions used in both eTool and CENTURY modelling tools and the results are therefore indicative only.

\section{DISCUSSION}

The aim of the model is to identify the significant carbon emission sources and potential sinks to inform communities about the significant sources and sinks in their domain, and also for comparison with others. This information can then be used to identify potential benefits to residents in terms of energy savings that could lead to reduced costs and also potential programs that could lead to revenue streams in the low carbon 
economy. For example the high incidence of transport emissions may indicate an opportunity to the community to look at alternative transport fuels such as bio-diesel. The potential to manufacture their own fuel and supply to visitors or neighbouring communities and organisations as a commercial enterprise could be investigated. Alternatively, longer-term solutions such as electric vehicles might be considered for shortrange trips and combined with solar energy systems to reduce their operating energy needs that are also significant. These options will also need to be considered in terms of the marginal cost of abatement.

The relatively low carbon removals provided by the land area could indicate that further abatement could be achieved with different management practices such as vegetation projects and fire management. These abatement programs would need to be discussed with and selected by the community to ensure they align with their needs, goals and cultural preferences.

Cost, revenue and other benefit information can be added to the basic model at a later date when it is more fully developed. It should be noted that methods for calculating carbon removals under the Carbon Farming Initiative need to be submitted for approval (DCCEE, 2011a) and this model is not intended to provide the detail required for that process. For instance consideration needs to be given to leakage aspects of carbon management programs, such as destocking areas, to ensure that carbon emissions are reduced and not merely relocated elsewhere. Also any increase in emissions incurred in implementing the project must be included to ensure net emissions are calculated accurately and rules regarding additionality and permanence would need to be met. When the CFI methods have been determined there is potential to include those within the model parameters.

\section{CONCLUSION}

If Australia is to realise its commitment to reducing carbon emissions and the resulting impact on its citizens, greenhouse gas sources and sinks need to be measured and evaluated. Assessment at a community level that encompasses all significant sources and sinks within its domain provides a mechanism for modelling a range of scenarios for comparison with a business as usual approach. It is intended that the results from this model would form the basis for selecting appropriate further action at the local level that accords with the residents' preferences. In the case of Indigenous communities, the Federal Government's concurrent commitment to 'close the gap' on Indigenous disadvantage could also be assisted by this approach. The carbon mitigation opportunities identified as a result of the modelling process have the potential to provide a suite of benefits to remote communities including economic development through a range of carbon-related services to industry and society. This model is currently being applied in three remote Aboriginal communities in Australia and the results of the modelling will be published in a future paper.

\section{ACKNOWLEDGEMENTS}

Funding for this research, which is part of the Decarbonising Cities and Regions Project, is from the Australian Research Council - Linkage Program (LP 0990631), and industry sponsors Horizon Power and Parsons Brinckerhoff.

\section{REFERENCES}

Alchin, M., Tierney, E., and Chilcott, C. (2010). Carbon Capture Project Final Report: An evaluation of the opportunity and risks of carbon offset based enterprises in the Kimberley-Pilbara region of Western Australia, Department of Agriculture and Food WA, Perth, Australia.

Australian Bureau of Statistics (2007). Housing and Infrastructure in Aboriginal and Torres Strait Islander Communities, Australia, 2006, Australian Government, Canberra.

Beale, T. (2006). Energy Service Levels for Remote Indigenous Communities, in: G. Ho, K. Mathew, and M. Anda (Eds), Sustainability of Indigenous Communities in Australia, Murdoch University, Perth, Western Australia.

Colorado State University (undated). Century Model. http://www.nrel.colostate.edu/projects/century/

Department of Climate Change and Energy Efficiency (DCCEE) (2011a). Carbon Credits (Carbon Farming Initiative) Bill 2011: Explanatory memorandum. 
Stewart et al., Developing a model for carbon sinks and sources for Indigenous communities in Australia

Department of Climate Change and Energy Efficiency (DCCEE) (2011b). Australian National Greenhouse Accounts: National Inventory Report 2009, Australian Government.

Eady, S., Grundy, M., Battaglia, M., and Keating, B. (2009). An Analysis of Greenhouse Gas Mitigation and Carbon Sequestration Opportunities from Rural Land Use, CSIRO, St Lucia, Queensland.

Griffiths, S., and Kinnane, S. (2011). Kimberley Aboriginal Caring for Country Plan: Healthy Country Healthy People: Right People Right Country Right Way, Nulungu Centre for Indigenous Studies, University of Notre Dame Australia.

Harper, R.J., Beck, A.C., Ritson, P., Hill, M.J., Mitchell, C.D., Barrett, D.J., Smettem, K.R.J., and Mann, S.S. (2007). The potential of greenhouse sinks to underwrite improved land management. Ecological Engineering 29:329-341.

Haynes, R., and Bruce, A. (2011). eTool Version 1, Phobos Consulting, Perth, Western Australia. http://etool.net.au/

International Energy Agency Annex 31 Project. (2004). Life cycle assessment methods for buildings, Ottawa.

IPCC (2006). 2006 IPCC Guidelines for National Greenhouse Gas Inventories, in: E. H. S. Prepared by the National Greenhouse Gas Inventories Programme, L. Buendia, K. Miwa, T. Ngara, and K. Tanabe (Eds), IGES, Japan, Hayama, Japan.

McDermott, R., O'Dea, K., Rowley, K., Knight, S., and Burgess, P. (1998). Beneficial impact of the Homelands Movement on health outcomes in central Australian Aborigines. Australian and New Zealand Journal of Public Health 22:653-658.

Newman, P.W.G. (1999) Sustainability and cities: extending the metabolism model. Landscape and Urban Planning 44:219-226. DOI: 10.1016/S0169-2046(99)00009-2.

Noble, I., Barson, M., Dumsday, R., Friedel, M., Hacker, R., McKenzie, N., Smith, G., Young, M., Maliel, M., and Zammit, C. (1996). Land resources, Australia: State on the Environment, CSIRO, Collingwood. pp. 6.1-6.55.

SCRGSP (Steering Committee for the Review of Government Service Provision) (2009). Overcoming Indigenous Disadvantage: Key Indicators 2009, Productivity Commission, Canberra.

Standards Australia (1998). 14040:1998 Environmental Management - Life cycle assessment - Principles and framework Standards Australia, Homebush.

Wright, R.T. (2005). Environmental Science: Toward a Sustainable Future. 9th ed. Pearson Prentice Hall, Upper Saddle River, NJ. 